\title{
Antimicrobial Effects of Punica granatum Extracts on Staphylococcus aureus, Streptococcus mutans, Lactobacillus acidophilus, Enterococcus faecalis and Candida albicans
}

\author{
S. Aravindraj ${ }^{*}$, M. Preethi and B. Sivapathasundharam \\ Department of oral Pathology and Microbiology Meenakshi Ammal Dental College Alapakkam \\ Maduravoyal, Chennai 600095, Tamil Nadu, India \\ *Corresponding author
}

\section{A B S T R A C T}

\begin{tabular}{|l|}
\hline Ke y w or d s \\
Punica granatum, \\
Antimicrobial \\
activity. \\
\hline Article Info \\
\hline Accepted: \\
26 August 2017 \\
Available Online: \\
10 September 2017 \\
\hline
\end{tabular}

An antimicrobial is a substance that kills or inhibits the growth of microorganisms. The use of medicinal plants to treat dental diseases has been discussed from time to time and one of which is Punica granatum. This study aims at evaluating the antimicrobial effects of various extracts of Punica granatum against Staphylococcus aureus, Streptococcus mutans, Lactobacillus acidophilus, Enterococcus faecalis and Candida albicans to find its antimicrobial efficacy

\section{Introduction}

An antimicrobial is a substance that kills or inhibits the growth of micro-organisms. On the basis of mode of action, antimicrobials are classified into two broad categories as Microbicidal that kill microbes without leaving any option for their survival and Microbiostatic that cease all the metabolic activities of microbes that are important for their survival. They are called as growth inhibitors of microbes ${ }^{1}$.

The history of antimicrobials begins with the observation of Pasteur and Joubert who discovered that one type of microbe could prevent the growth of other. That growth inhibition was due to secretion of a compound, later called as Antibiotic. Nowadays the term antibiotics is not confined to secretions of microbes only but also includes all those synthetic drugs that help body to get rid of any bacterial infection. The discovery of antimicrobials like Penicillin and Tetracycline paved way for better health of people in the world by curing infectious diseases

The widespread use of commercially available antimicrobials led to the emergence of antimicrobial resistant pathogens that ultimately led to the threat to global public health. All commercially available antibiotics with prolonged use may have negative effect 
on human health because they kill gut flora, so human beings need to take probiotics to replace the killed gut flora. All the above points make a clear way for the use of herbal antimicrobials. The use of plants for treating diseases is as old as the human civilization. There are many plants which have been in use as traditional medicine, and called as medicinal plants. The interest in evaluating therapeutic effects of plants have increased dramatically with more and more people inclining toward alternative medicine for their health care needs as they are effective, nontoxic, and economical and usually have no side effects. The use of plants for curing diseases was inevitable as is already proven by seeing the problems associated with synthetic antibiotics. The use of medicinal plants to treat dental diseases has been discussed from time to time by many researchers and one of which is Punica granatum. Different part of pomegranate like bark, leaves, immature fruits, and fruit have some medicinal significance. ${ }^{1-3}$

The bacterial flora of the mouth is among the most diverse of any of the resident flora associated with humans. The dental tissues enamel, dentin, and cementum constitute the oral solid surfaces coated by a pellicle to which the microbial cells attach. The primary colonizers and secondary organisms stick to each other on the surface of teeth and generate a matrix of exopolysaccharide within which cells grow, forming a community with a collective physiology. The resulting biofilm formed, known as dental plaque, subjects the teeth and gingival tissues to high concentrations of microbial metabolites which result in dental disease. ${ }^{3-5}$

Certain bacterial strains of like Streptococcus, Staphylococcus, Lactobacilli, Enterococcus and fungi like Candida reside in oral cavity and are known to cause infections in oral cavity.
This study aims at evaluating the microbial effects of the various extracts of Punica granatum against Staphylococcus aures, Streptococcus mutans, Lactobacillus acidophilus, Enterococcus faecalis and Candida albicans to find its antimicrobial efficacy.

\section{Materials and Methods}

The present in- vitro study was conducted to evaluate the antimicrobial efficacy of crude solvent extract of Punica granatum against five test organisms namely Staphylococcus aureus, Streptococcus mutans, Lactobacillus acidophilus and Candida albicans. The solvent extraction and antimicrobial bioassay of the selected fruit (Punica granatum) were done in the Department of Microbiology and Central research Lab, Meenakshi Ammal Dental College and hospital, Maduravoyal, Chennai.

\section{Armamentarium-I}

Hot air oven, Incubator, Orbital shaking incubator, Electronic Weighing machine, Electric grinder, Punica granatum (peels, arils and seeds and exocarp), Solvents: Ethanol, Methanol, Acetone, Ethylacetate, Choloroform, Hexane, Dimethyl sulfoxide, Glass measuring jar, Test tubes (Hi-media laboratories),conical flask, Whatman filter paper (No.1), Sterile de- ionized distilled water.

\section{Armamentarium-II}

Inoculating wire loop, Micropipette (V3 variable volume pipette $2 \mu 1-1000 \mu 1)$, Sterile micropipette tips, Standard antibiotic zone measuring Scale (Himedia Laboratories), Petri plates, Five Strains of Micro- organisms) Staphylococcus aureus (MTCC 6908), b) Streptococcus mutans (MTCC 497), c) Lactobacillus acidophilus (MTCC 10307), d) 
Enterococcus faecalis (ATCC 29212),e) Candida albicans (MTCC 4748), Thioglycolate broth, Brain heart infusion broth, Tryptone soya broth, MTS broth, Sabouraud dextrose broth, Mueller Hinton Agar, Blood Agar, MRS Agar, Sabouraud dextrose Agar, MacConkey Agar.

\section{Procedure}

\section{Collection of pomegranate}

Pomegranate (Punica granatum) weighing $7 \mathrm{Kgs}$ in total were purchased from Koyembedu fruit market, chennai. The fresh fruits were cleaned and washed under running tap water and air dried. The peels, arils and seeds and exocarp (leathery skin) of pomegranate were separated into three samples- Sample I -Peels, Sample II- Arils and Seeds, and Sample III- Exocarp. All the samples were oven dried for about $30^{\circ} \mathrm{c}$ for 7 days and blended in an electric grinder and fine powders were obtained. They were transferred to the test tubes and labelled.

\section{Test organisms}

The Standard bacterial and fungal strains were procured from Microbial Type Culture Collection and gene bank (MTCC), Chandigarh, India and American Type Culture Collection (ATCC), Manassas, Virginia, United States of America by the Department of microbiology and Central research lab, Meenakshi Ammal dental college and hospital, Chennai.

The antibacterial and antifungal sensitivity test was carried out in the same place for the following test organisms: Staphylococcus aureus (MTCC 6908), Streptococcus mutans (MTCC 497), Lactobacillus acidophilus (MTCC 10307), Enterococcus faecalis (ATCC 29212) and Candida albicans (MTCC 4748).
Crude solvent extraction as represented in Armamentarium-I

The powdered samples of pomegranate were weighed using electronic weighing machine. $10 \mathrm{gms}$ of powdered pomegranate Sample I (Peels), Sample II (Arils and Seeds), Sample III (Exocarp) was dissolved in $30 \mathrm{ml}$ of the solvents selected for the study, in test tubes. The constituents were mixed well and kept in orbital shaking incubator for 48 hours. The filtration of solvent- powder mixture and transferred into pre-weighed Petri plates. The extracts were left for evaporation in a dry place for 2 days. After complete evaporation, the plates were weighed again for detecting the amount of crude extract obtained from each solvent. The crude extracts were then reconstituted in dimethyl sulfoxide (DMSO), which is an inert organic solvent, to prepare a concentration of $10 \mathrm{mg} / \mathrm{ml}$. These reconstituted extracts were transferred to the sterile labelled vials and were stored in refrigerator $\left(4^{\circ} \mathrm{C}\right)$ until use.

\section{Antimicrobial Bioassay}

\section{Inoculum preparation}

The lyophilized cultures were added to Brain heart infusion broth for Staphylococcus aureus and Enterococcus faecalis, Thioglycolate broth for Streptococcus mutans, MRS broth for Lactobacillus acidophilus, Sabouraud dextrose broth for Candida albicans. The aerobic broth was incubated at $37^{\circ} \mathrm{c}$ for 2 hours in a candle jar. After incubation, the broths with turbidity were adjusted to McFarland Standard and were used as the inoculums.

\section{Agar disc diffusion method as represented in Armamentarium-II}

The antimicrobial activities of the isolates on different extracts were tested using the agar diffusion method. Lawn cultures were made 
onto sterile Muller Hinton Agar (Staphylococcus aureus), Blood Agar (Streptococcus mutans), MacConkey Agar (Enterococcus faecalis), Sabouraud dextrose Agar (Candida albicans), MRS Agar (Lactobacillus acidophilus) with sterile cotton swabs. Six discs measuring $6 \mathrm{~mm}$ each were loaded with six solvent extracts and one negative control, dimethyl sulfoxide (DMSO). $10 \mu 1$ of the reconstituted extracts, were loaded into each respective discs using a micropipette. The same procedure was done for all the test pathogens under study. The discs were then placed onto the surface of agar as six in each plate. Positive controls for each of the organisms were carried out separately using a standard antibacterial drug, Erythromycin and standard antifungal drug, ketoconazole. The aerobic plates were then incubated at $37^{\circ} \mathrm{c}$ for 24 hours. The extracts showing the zone of inhibition for each test organism were observed and measured using a standard antibiotic zone measuring scale and recorded in millimeters. The Experiment was repeated five times and the mean zone of inhibition was calculated.

\section{Results and Discussion}

The results were interpreted by measuring and recording the zone of inhibition for each test organism in millimetres. The mean values of all the experiments were calculated and the DATA was statistically analyzed by Descriptive Mean Difference Table. Multiple comparisons among the organisms and the solvent extracts were analyzed using TUKEY POST HOC TEST. All the statistical analyses were done using SPSS version 19.0.

The mean values of zones of inhibition of individual organisms against different solvent extracts of Punica granatum Peels (Sample I) are represented in table 1 and figure 1 . The mean values of zones of inhibition of individual organisms against different solvent extracts of Punica granatum Arils and Seeds (Sample II) are represented in table 2 and figure 2 .

The mean values of zones of inhibition of individual organisms against different solvent extracts of Punica granatum Exocarp (Sample III) are represented in table 3 and figure 3 . Erythromycin was used as the standard antibiotic and ketoconazole was used as the standard antifungal for positive control and Dimethyl sulfoxide (DMSO) was used as negative control.

Table 4 signifies that there is a significant statistical difference among the solvent extracts of all the samples of Punica granatum against Staphylococcus aureus, Streptococcus mutans, Lactobacillus acidophilus, Enterococcus faecalis and Candida albicans at $\mathrm{p}<0.05$ as determined by ONE WAY ANOVA. If the $\mathrm{P}$ value $<0.05$ it is considered as significant, if the $\mathrm{P}$ value is 0.000 , it is considered as highly significant.

Figure 4 shows the Comparison of antimicrobial efficacy of different solvent extracts of various samples of Punica granatum (Peels, Arils and seeds and Exocarp)

Table 5 signifies that there is a significant statistical difference between the different solvent extracts of all the samples of Punica granatum Peels (Sample I), Arils and seeds (Sample II) and Exocarp (sample III) against the test organisms at $p<0.05$ as determined by ANOVA. If the $\mathrm{P}$ value $<0.05$ is considered as significant, if the $\mathrm{P}$ value is 0.00 , it is considered as highly significant.

Figures 5, 6 and 7 show the effect of Punica granatum peels, seeds and epicarp against the test organisms respectively.

Methanol extacts of Punica granatum peels 
(Sample I) was proved to have good inhibitory effect, followed by exocarp (sample III) and arils and seeds (Sample II) among the three pomegranate samples used against the test organisms.

Ethanol extracts of Punica granatum peels (Sample I) was proved to have good inhibitory effect, followed by arils and seeds (Sample II) and exocarp (sample III) among the three pomegranate samples used against the test organisms.

Ethyl Acetate extracts of Punica granatum peels (Sample I) was proved to have a good inhibitory effect, followed by exocarp (sample III) and arils and seeds (Sample II) among the three pomegranate samples used against the test organisms. Acetone extracts of Punica granatum peels (Sample I) was proved to have a good inhibitory effect, followed by exocarp (sample III) and arils and seeds (Sample II) among the three pomegranate samples used against the test organisms.

Chloroform extracts of Punica granatum peels (Sample I) was proved to have a good inhibitory effect, followed by arils and seeds (Sample II) and exocarp (sample III) among the three pomegranate samples used against the test organisms.

Hexane extracts of Punica granatum exocarp (sample III) was proved to have a good inhibitory effect, followed by peels (Sample I) and arils and seeds (Sample II) among the three pomegranate samples used against the test organisms.

Table.1

Solvents used for crude extracts of Punica granatum peels (Sample I) Zone of inhibition (mean value in $\mathrm{mm}$ )

\begin{tabular}{|c|c|c|c|c|c|c|c|c|}
\hline Test organisms & M & E & EA & A & CF & H & PC & NC \\
\hline S.aureus & 20 & 18 & 14 & 18 & 12 & 8 & 25 & 0 \\
\hline S.mutans & 20 & 22 & 18 & 22 & 15 & 8 & 35 & 0 \\
\hline L.acidophilus & 14 & 17 & 14 & 12 & 12 & 0 & 33 & 0 \\
\hline E.faecalis & 18 & 16 & 18 & 20 & 12 & 8 & 25 & 0 \\
\hline C.albicans & 14 & 12 & 12 & 14 & 10 & 10 & 25 & 0 \\
\hline
\end{tabular}

Table.2

\begin{tabular}{|l|c|c|c|c|c|c|c|c|}
\hline \multicolumn{7}{|c|}{ Solvents used for crude extracts of Punica granatum } \\
arils \& seeds (Sample II) \\
\begin{tabular}{|l|r|r|r|r|r|r|r|r|} 
Zone of inhibition (mean value in mm) \\
organisms
\end{tabular} & M & E & EA & A & CF & H & PC & NC \\
\hline S.aureus & 18 & 18 & 18 & 18 & 7 & 0 & 34 & 0 \\
\hline S.mutans & 0 & 0 & 0 & 0 & 0 & 8 & 34 & 0 \\
\hline L.acidophilus & 0 & 0 & 0 & 0 & 10 & 0 & 35 & 0 \\
\hline E.faecalis & 16 & 18 & 18 & 20 & 12 & 0 & 35 & 0 \\
\hline C.albicans & 12 & 9 & 10 & 8 & 0 & 0 & 25 & 0 \\
\hline
\end{tabular}




\section{Table.3}

\begin{tabular}{|c|c|c|c|c|c|c|c|c|}
\hline \multicolumn{9}{|c|}{$\begin{array}{l}\text { Solvents used for crude extracts of Punica granatum exocarp (Sample III) } \\
\text { Zone of inhibition (mean value in } \mathrm{mm} \text { ) }\end{array}$} \\
\hline $\begin{array}{l}\text { Test } \\
\text { organisms }\end{array}$ & $\mathrm{M}$ & $\mathrm{E}$ & EA & A & $\mathrm{CF}$ & $\mathrm{H}$ & $\mathrm{PC}$ & $\mathrm{NC}$ \\
\hline S.aureus & 16 & 16 & 16 & 13 & 0 & 0 & 35 & 0 \\
\hline S.mutans & 14 & 0 & 14 & 16 & 14 & 14 & 30 & 0 \\
\hline L.acidophilus & 18 & 16 & 20 & 18 & 0 & 0 & 35 & 0 \\
\hline E.faecalis & 0 & 0 & 0 & 16 & 14 & 14 & 35 & 0 \\
\hline C.albicans & 14 & 10 & 12 & 8 & 0 & 8 & 25 & 0 \\
\hline
\end{tabular}

Table.4

ONE WAY ANOVA

\begin{tabular}{|c|c|c|c|c|c|c|}
\hline & & Sum of Squares & Df & $\begin{array}{c}\text { Mean } \\
\text { Square }\end{array}$ & $\mathrm{F}$ & Sig. \\
\hline S.aureus & $\begin{array}{l}\text { Between Groups } \\
\text { Within Groups } \\
\text { Total }\end{array}$ & $\begin{array}{l}7649.048 \\
1106.667 \\
8755.714\end{array}$ & $\begin{array}{r}6 \\
98 \\
104\end{array}$ & $\begin{array}{r}1274.841 \\
11.293\end{array}$ & 112.893 & .000 \\
\hline S.mutans & $\begin{array}{l}\text { Between Groups } \\
\text { Within Groups } \\
\text { Total }\end{array}$ & $\begin{array}{r}6879.524 \\
5800.667 \\
12680.190 \\
\end{array}$ & $\begin{array}{r}6 \\
98 \\
104 \\
\end{array}$ & $\begin{array}{r}1146.587 \\
59.190\end{array}$ & 19.371 & .000 \\
\hline L acidophilus & $\begin{array}{l}\text { Between Groups } \\
\text { Within Groups } \\
\text { Tota1 }\end{array}$ & $\begin{array}{r}10075.714 \\
4165.333 \\
14241.048 \\
\end{array}$ & $\begin{array}{r}6 \\
98 \\
104 \\
\end{array}$ & $\begin{array}{r}1679.286 \\
42.503\end{array}$ & 39.509 & .000 \\
\hline E.faecalis & $\begin{array}{l}\text { Between Groups } \\
\text { Within Groups } \\
\text { Total }\end{array}$ & $\begin{array}{l}5814.990 \\
3968.400 \\
9783.390 \\
\end{array}$ & $\begin{array}{r}6 \\
98 \\
104 \\
\end{array}$ & $\begin{array}{r}969.165 \\
40.494\end{array}$ & 23.934 & .000 \\
\hline C.albicans & $\begin{array}{l}\text { Between Groups } \\
\text { Within Groups } \\
\text { Total }\end{array}$ & $\begin{array}{r}4290.000 \\
833.333 \\
5123.333\end{array}$ & $\begin{array}{r}6 \\
98 \\
104\end{array}$ & $\begin{array}{r}715.000 \\
8.503\end{array}$ & 84.084 & .000 \\
\hline
\end{tabular}

Table.5

ONE WAY ANOVA

\begin{tabular}{|c|c|c|c|c|c|c|}
\hline & & Sum of Squares & df & $\begin{array}{l}\text { Meaan } \\
\text { Square }\end{array}$ & $\mathrm{F}$ & Sig. \\
\hline $\mathrm{M}$ & $\begin{array}{l}\text { Between Groups } \\
\text { Within Groups } \\
\text { Total }\end{array}$ & $\begin{array}{r}810.667 \\
2746.000 \\
3556.667\end{array}$ & $\begin{array}{r}2 \\
72 \\
74\end{array}$ & $\begin{array}{r}405.333 \\
38.139\end{array}$ & 10.628 & .000 \\
\hline $\mathrm{E}$ & $\begin{array}{l}\text { Between Groups } \\
\text { Within Groups } \\
\text { Total } \\
\end{array}$ & $\begin{array}{l}1152.667 \\
3204.000 \\
4356.667 \\
\end{array}$ & $\begin{array}{r}2 \\
72 \\
74 \\
\end{array}$ & $\begin{array}{r}576.333 \\
44.500\end{array}$ & 12.951 & .000 \\
\hline EA & $\begin{array}{l}\text { Between Groups } \\
\text { Within Groups } \\
\text { Total }\end{array}$ & $\begin{array}{r}450.667 \\
2938.000 \\
3388.667 \\
\end{array}$ & $\begin{array}{r}2 \\
72 \\
74 \\
\end{array}$ & $\begin{array}{r}225.333 \\
40.806\end{array}$ & 5.522 & .006 \\
\hline A & $\begin{array}{l}\text { Between Groups } \\
\text { Within Groups } \\
\text { Total }\end{array}$ & $\begin{array}{r}887.707 \\
2364.640 \\
3252.347 \\
\end{array}$ & $\begin{array}{r}2 \\
72 \\
74 \\
\end{array}$ & $\begin{array}{r}443.853 \\
32.842 \\
\end{array}$ & 13.515 & .000 \\
\hline CF & $\begin{array}{l}\text { Between Groups } \\
\text { Within Groups } \\
\text { Total }\end{array}$ & $\begin{array}{r}704.667 \\
1890.000 \\
2594.667 \\
\end{array}$ & $\begin{array}{r}2 \\
72 \\
74 \\
\end{array}$ & $\begin{array}{r}352.333 \\
26.250\end{array}$ & 13.422 & .000 \\
\hline $\mathrm{H}$ & $\begin{array}{l}\text { Between Groups } \\
\text { Within Groups } \\
\text { Total }\end{array}$ & $\begin{array}{r}488.000 \\
1570.000 \\
2058.000\end{array}$ & $\begin{array}{r}2 \\
72 \\
74\end{array}$ & $\begin{array}{r}244.000 \\
21.806\end{array}$ & 11.190 & .000 \\
\hline
\end{tabular}


Fig.1

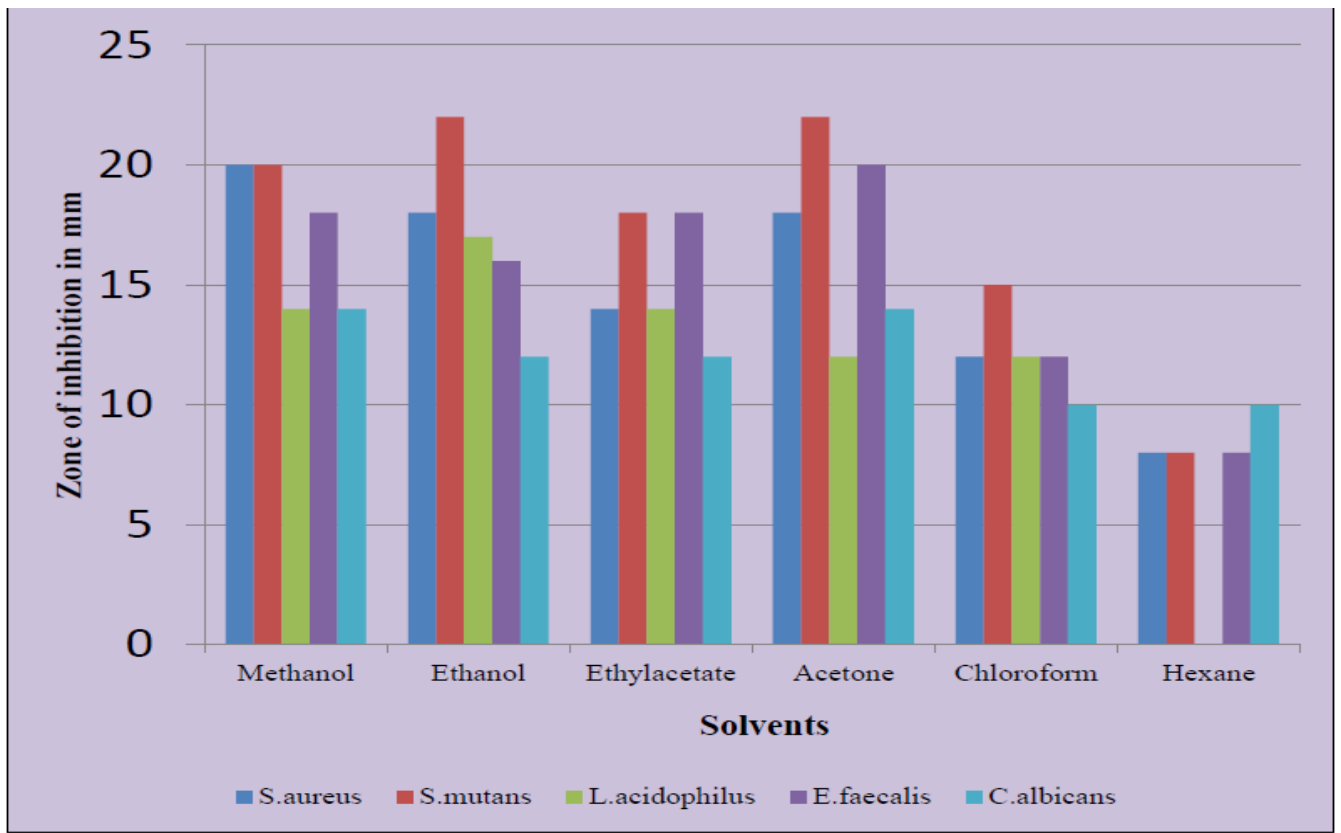

Fig.2

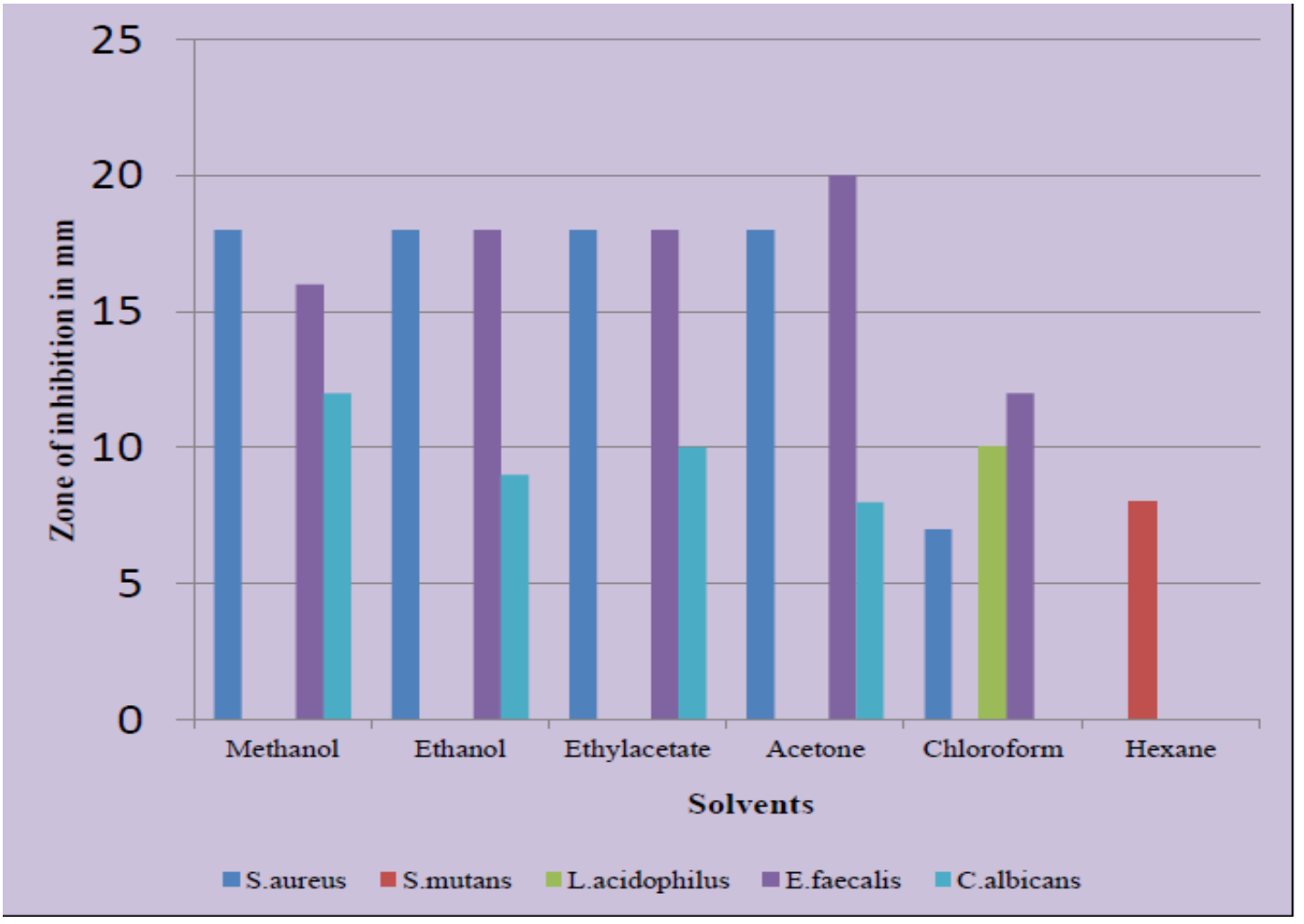


Fig.3



Fig.4

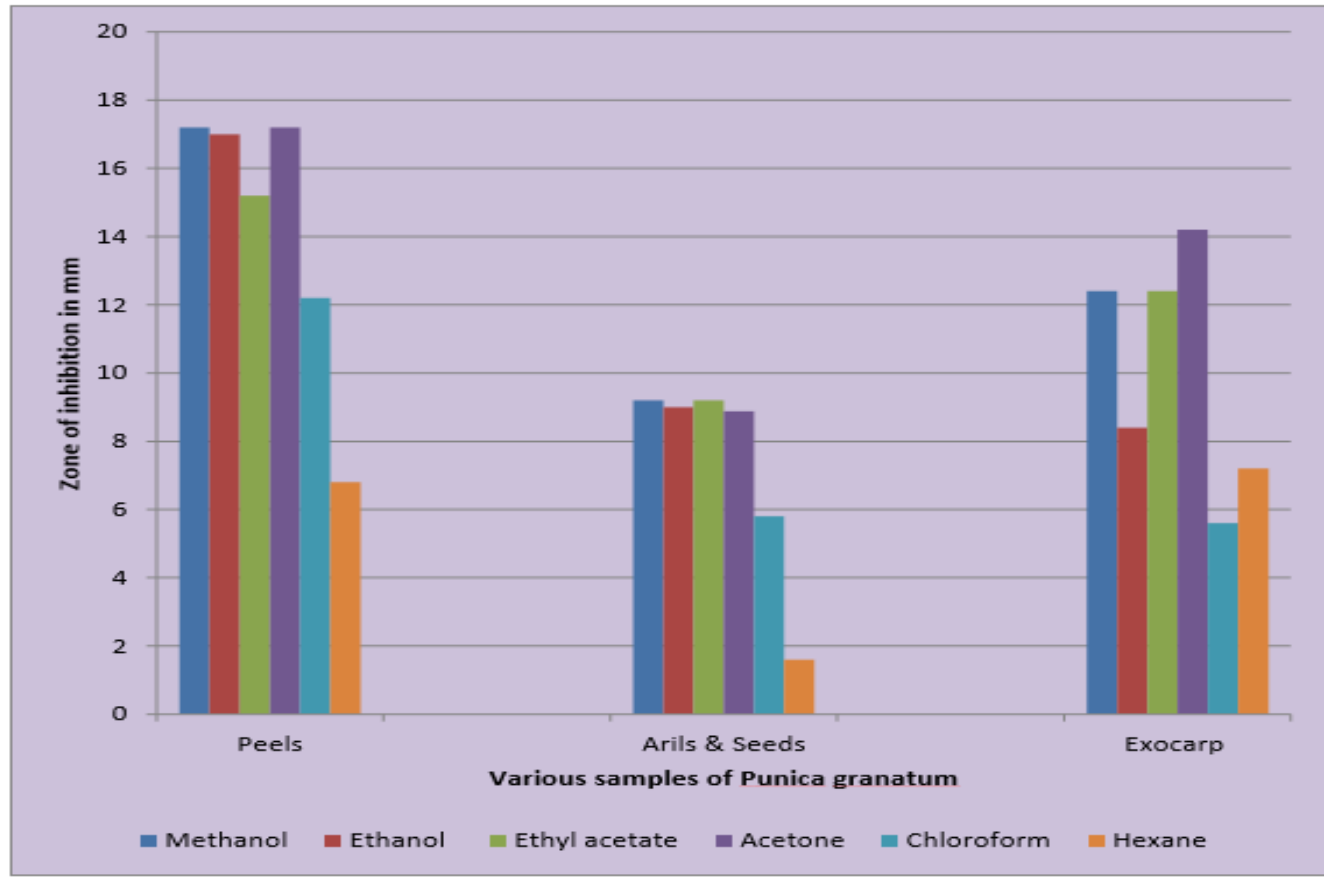


Fig.5

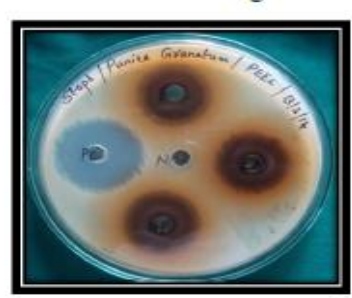

Staphylococcus aureus

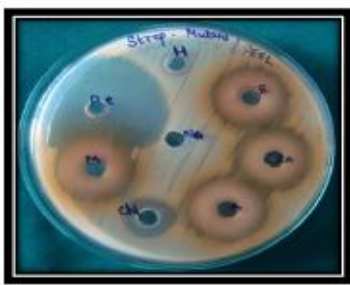

Streptococcus mutans

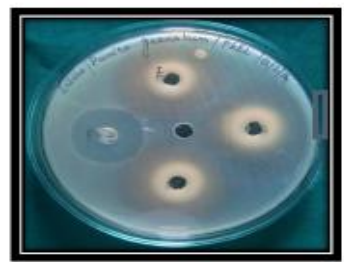

Enterococcus faecalis

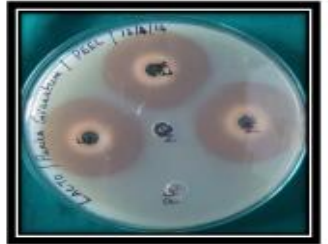

Lactobacillus acidophilus

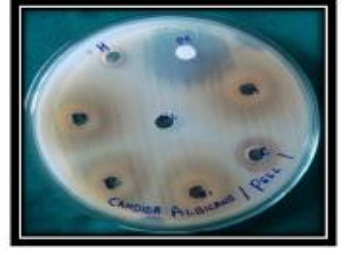

Candida albicans

Fig.6

Efffects of various solvent extracts of Punica granatum Exocarp (Sample III) against the test organisms

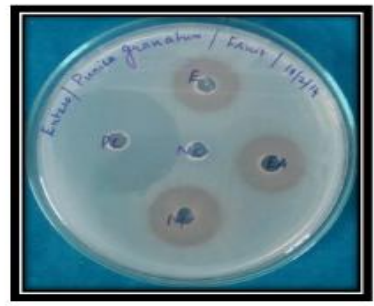

Enterococcus faecalis

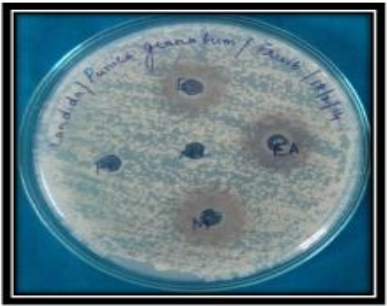

Candida albicans

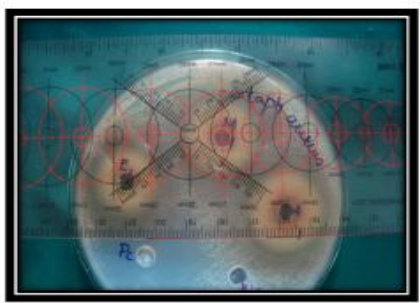

Measuring the zone of inhibition using standard antibiotic zone measuring scale (Hi-media Laboratories) 
Fig.7

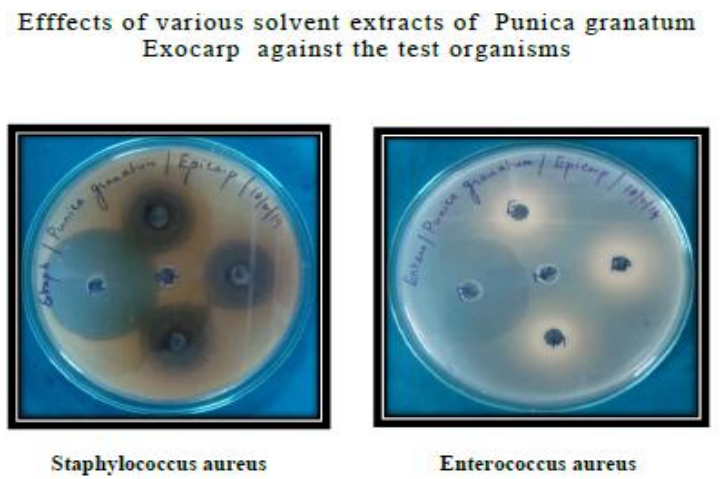

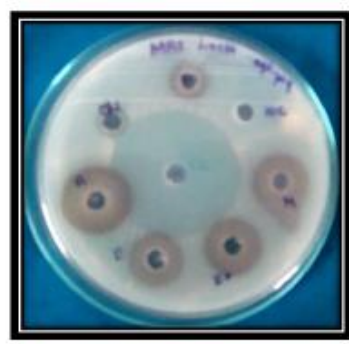

Lactobacillus acidophilus

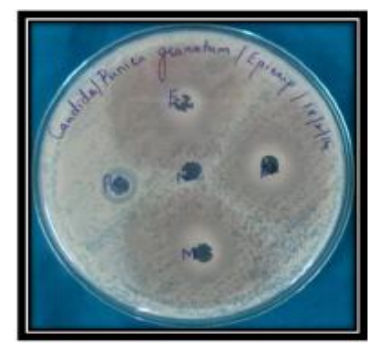

Candida albicans
Among the three pomegranate samples used in this study against the different test organisms, Punica granatum peels (Sample I) was proved to have a good inhibitory effect followed by exocarp (sample III) and arils and seeds (Sample II).

Dental diseases are a multifactorial disease and have affected many populations throughout the world. The normal oral flora comprises a diverse group of microorganisms including bacteria, fungi, protozoa and even possibly viruses. Occurrence of disease results from disturbance of the equilibrium of this complex ecosystem, where population shift leads to over representation of pathogenic species which contribute to the onset and progression of the most common oral diseases, caries and periodontal disease. ${ }^{5,6}$

We have chosen Punica granatum for the present study to evaluate its effectiveness in the five microorganisms namely Staphylococcus aureus, Streptococcus mutans, Lactobacillus acidophilus, Enterococcus faecalis and Candida albicans which are found to be common causative organisms of oral diseases. In the present work, different organic solvent extracts of Punica granatum (Peels, Arils and seeds and Exocarp) were prepared using acetone, methanol, ethylacetate, ethanol, chloroform and hexane. The prepared extracts were screened for their antimicrobial activity against five organisms namely Staphylococcus aureus, Streptococcus mutans, Lactobacillus acidophilus, Enterococcus faecalis and Candida albicans by using Agar Disc Diffusion method. The best suitable solvent and extract was further optimized from the results of antimicrobial assay. Positive controls for each of the organisms were carried out separately using a standard antibacterial drug, Erythromycin and standard antifungal drug, ketoconazole 
Punica granatum peels (Sample I) was proved to have a good inhibitory effect, The various extracts of Punica granatum was found to be effective against the test organisms but when compared to standard antibiotics the extracts was found to be less effective against the test organisms

In association with the present study Saad Sabbar Dahham et al., (2010) reported that methanolic extracts of pomegranate are more effective against bacteria and fungi than the aqueous extracts, the highest antibacterial activity was recorded against Staphylococcus aureus and among fungi high activity against Aspergillus niger was recorded.

As far as $S$. aureus and $S$. epidermidis is considered, methanolic extracts of Punica granatum peel had good antibacterial activity in other similar studies done by Sh. Abdollahzadeh et al., (2011) and S. Vijayanand et al., (2011).

The antimicrobial activity of Punica granatum peel extracts might be due to the presence of phytocompounds in the Punica granatum peel extracts like hydrolysable tannins, polyphenolics and flavonoids. Specifically punicalagin, gallagic acid, catechin, quercetin and rutin. Tannins may act on the cell wall and across the cell membrane because they can precipitate proteins. They may also suppress many enzymes such as glycosyltransferases. Polyphenols may affect the bacterial cell wall, inhibit enzymes by oxidized agents, interact with proteins and disturb co-aggregation of microorganisms ${ }^{8-10}$

The present study results were fluctuant with Amina Chebaibi and Fouzia Rhazi Filali (2012). They reported that aqueous extracts of Moroccan pomegranate peel have great potential as antibacterial compounds against several microorganisms. The pomegranate fruit peel extract was found to be more or equally effective as compared to standard antibiotics ${ }^{11}$. Whereas in the present study the pomegranate peel was found to be less effective as compared to standard antibiotics probably because the pomegranate used is of Indian orgin, it may have varied chemical composition when compared to Moroccan pomegranate. The chemical composition of fruits differs depending on the cultivar, growing region, climate, maturity, culture practice and storage. ${ }^{11}$ The present study results were also consistent with Eliana Harue Endo et al., (2010) where it is observed that activity-guided repeated fractionation of crude hydro alcoholic (ethanolic) extract prepared from the fruit peels of Punica granatum on a silica-gelcolumn yielded a compound (Punicalagin) that exhibited strong antifungal activity against Candida species ${ }^{12}$.

The present study was in accordance with the study conducted by Mahsa Shafighi (2012), she stated that methanolic extract of pomegranate peel, flower, leaf and stem showed high antifungal against Candida albicans. It is expected that this ability is referring to high amounts of phenol and tannins In the Punica granatum, there are Flavonoids (Such as Quercetin, Rutin, Naringen-in, Luteolin, Pelargonidin, Prodelphindin, Kaempferol and Flavan) and Tannins (including Methyl gallate, Methyl Ellagic acid and Peduncalgin). This provides a complementary preventive value for this plant and supports its gaining popularity as an antifungal source. ${ }^{13}$

The present study can serve as a prime tool to analyse the antimicrobial efficacy of various extracts of Punica granatum against the selected oral pathogens. It also helps to check, which extract of Punica granatum has got high antimicrobial efficacy among the various extracts, which are peels, arils and seeds and exocarp of Punica granatum. The present study is time-saving, economical, effective, 
non-toxic and the samples are easily available. Punica granatum can be used in the treatment of infectious diseases caused by resistant microbes. The synergistic effect from the association of antibiotic with Punica granatum extracts against resistant pathogens leads to new choices for the treatment of infectious diseases. This effect enables the use of the respective antibiotic when it is no longer effective by itself during therapeutic treatment.

The Punica granatum parts or the compounds derived from the plants are now established recipe of both pharmaceuticals and nutraceuticals. Many new drugs can be developed from Punica granatum to control several diseases with no side effects as it is from natural source. A typical research and developmental work needs to be carried out for its better therapeutic and commercial utilization

Apart from developing new drugs from Punica granatum, Pomegranate gel and Pomegranate mouth wash can be developed. Pomegranate gel - a gel containing extracts of pomegranate can be used as a antibacterial and antifungal agents. Pomegranate mouth rinse- extracts from Punica granatum as an antiplaque and antigingivitis agent.

Although, considerable evidence exists regarding the antibacterial and antifungal properties of Punica granatum, further human trials are necessary to refute or substantiate these properties.

\section{References}

1. Abdollahzadeh, Sh., RY. Mashouf, H. Mortazavi, MH. Moghaddam N. Roozbahani, M. Vahedi. Antibacterial and antifungal activities of Punica granatum peel extracts against oral pathogens. Journal of dentistry $2011 ; 8(1)$ : 1-6.
2. Ali Sadeghian, Ahmad Ghorbani, Ahmad Mohamadi-Nejad, Hassan Rakhshandeh. Antimicrobial activity of aqueous and methanolic extracts of pomegranate fruit skin. Avicenna journal of phytomedicine 2011; 1(2): 67-73.

3. Amina Chebaibi and Fouzia Rhazi Filali. Bactericidal activity and phytochemical screening of Moroccan pomegranate peel aqueous extracts. Journal of medical plants research 2013; 7(14): 887-891.

4. Bowden G.H.W., and I. R. Hamilton. Survival of Oral Bacteria. Critical reviews in oral biology and medicine 1998; 9(1): 54-85.

5. Eliana Harue Endo, Diogenes Aparıcio Garcia Cortez, Tania Ueda-Nakamura, Celso Vataru Nakamura, Benedito Prado Dias Filho. Potent antifungal activity of extracts and pure compound isolated from pomegranate peels and synergism with fluconazole against Candida albicans. Research in microbiology 2010; 161: 534540.

6. Jahir Alam Khan, Sonali Hanee. Antibacterial properties of Punica granatum peels. International journal of applied biology and pharmacological technology 2011; 2(3): 2327.

7. Jorn A. Aas, Bruce J. Paster, Lauren N. Stokes, Ingar Olsen, Floyd E. Dewhirst. Defining the normal bacterial flora of the oral cavity. Journal of clinical microbiology 2005; 43(11): 5721-5732. 7. G. H.W. Bowden and I. R. Hamilton. Survival of Oral Bacteria. Critical reviews in oral biology and medicine 1998; 9(1): 54-85.

8. Jorn A. Aas, Bruce J. Paster, Lauren N. Stokes, Ingar Olsen, Floyd E. Dewhirst. Defining the normal bacterial flora of the oral cavity. Journal of clinical microbiology 2005; 43(11): 5721-5732. 7. G. H.W. Bowden and I. R. Hamilton. Survival of Oral Bacteria. Critical reviews 
in oral biology and medicine 1998; 9(1): 54-85.

9. Mahsa Shafighi, Leila Amjad, Mahboobeh Madani. In vitro antifungal activity of methanolic extract of various parts of Punica granatum. International journal of scientific and engineering 2012; 3(12): 1-4.

10. Saad Sabbar Dahham, Mir Naiman Ali, Hajera Tabassum and Mazharuddin Khan. Studies on antibacterial and antifungal activity of pomegranate. AmericanEurasian journal of agriculture and environment sciences 2010; 9(3): 273-281. 75. Sh. Abdollahzadeh, RY. Mashouf, H. Mortazavi, MH. Moghaddam N. Roozbahani, M. Vahedi. Antibacterial and antifungal activities of Punica granatum peel extracts against oral pathogens. Journal of dentistry 2011; 8(1): 16.
11. Scully, C., and M. El-Kabir. Candida and Oral Candidosis: A review. Critical reviews in oral biology and medicine 1994; 5(2): 125-157. 9. Khalid H. Metwalli, Shariq A. Khan, Bastiaan P. Krom, Mary Ann Jabra-Rizk. Streptococcus mutans, Candida albicans and the human mouth: a sticky situation. Journal of PLOS pathogens 2013; 9(10): 1-5.

12. Sukanya Rajan, J Ravi, Aparna Suresh, Sanjeela Guru. Hidden secrets of „Punica granatum $^{\text {ee }}$ use and its effects on oral health: A short review. Journal of orofacial research 2013; 3(1): 38-41. 3

13. Vijayan, S., and, J. Hemapriya. In vitro antibacterial efficacy of peel and seed extracts of Punica granatum L. against selected bacterial strains. International journal of medico biological research 2011; 1(4)231-234.

\section{How to cite this article:}

Aravindraj, S., M. Preethi and Sivapathasundharam, B.2017. Antimicrobial Effects of Punica granatum Extracts on Staphylococcus aureus, Streptococcus mutans, Lactobacillus acidophilus, Enterococcus faecalis and Candida albicans. Int.J.Curr.Microbiol.App.Sci. 6(9): 2762-2774. doi: https://doi.org/10.20546/ijcmas.2017.609.341 